\title{
REDUÇÃO DO USO DE FORMALDEÍDO NO TRATAMENTO DA TRICODINÍASE EM TILÁPIAS
}

\author{
DECREASING OF FORMALDEHYDE USE ON TREATMENT OF TRICHODINIASIS \\ IN TILAPIA
}

L. O. ALVES ${ }^{1}$, G. M. R. VALLADÃO ${ }^{2}$, F. PILARSKI ${ }^{3}$

\section{RESUMO}

Neste estudo, objetivou-se a redução do uso do desinfetante formaldeído no tratamento da tricodiníase em tilápia do Nilo Oreochromis niloticus, um dos principais peixes cultivados no mundo. A efetividade de um protocolo terapêutico (banho único de 15 minutos) contendo $1 \mathrm{ml} / \mathrm{L}$ de formaldeído $+1 \%$ de cloreto de sódio (T1) comumente utilizado em pisciculturas e o potencial para redução de $50 \%(0,5 \mathrm{ml} / \mathrm{L}$ de formaldeído $+1 \%$ de cloreto de sódio - T2) e $75 \%(0,25 \mathrm{ml} / \mathrm{L}$ de formaldeído $+1 \%$ de cloreto de sódioT3) do uso do desinfetante foram avaliados. A fase larval dos peixes é a mais afetada pela doença efoi utilizada como modelo. Larvas de tilápias parasitadas (20/tanque) de piscicultura comercial foram distribuídas em 9 tanquesde plástico (três por tratamento). O parasitismo inicial foi registrado $(197,67 \pm 202,24$ tricodinídeos/peixe) através de análise parasitológica de 10 animais. O parasitismo final do tratamento foi baseado na análise de 18 animais por tratamento.A efetividade do tratamento foi calculada pela fórmula $\mathrm{ET}=100-(\mathrm{Dx} 100 / \mathrm{A})$. ET é a eficácia do tratamento (\%), D é a média de parasitos depois do tratamento e A é a média de parasitos antes do tratamento. Os dados foram submetidos à análise de variância one-way e teste de Tukey, usando o software R. Probabilidade menor ou igual a 0,05 foi considerada estatisticamente significativa. O protocolo $\mathrm{T} 1$ (100\% de formaldeído) matou $99,80 \pm 0,21 \%$ de tricodinídeos, resultado estatisticamente similar ( $>0.05)$ ao protocolo T2 $(50 \%$ de formaldeído), o qual foi eficaz em eliminar $98,51 \pm 0,89 \%$ dos parasitos. No entanto, o protocolo T3 (25\% de formaldeído) apresentou eficácia estatisticamente menor $(\mathrm{p}<0.05)$ comparado aos outros dois tratamentos. Não foram observadas mortalidades ou alteração de comportamento dos animais. O tratamento com metade de formaldeído provou-se tão eficaz quanto as concentrações comumente utilizadas nas pisciculturas sendo injustificado o uso de concentrações maiores no tratamento da tricodiníase.

PALAVRAS-CHAVE:FORMOL. PISCICULTURA. TILÁPIA. TRICHODINA.

AGRADECIMENTO:À FAPESP pela bolsa de estudo (2013/20067-2).

ÁREA TEMÁTICA: Doenças Parasitárias

\footnotetext{
${ }^{1}$ Graduando em Zootecnia - Faculdade de Ciências Agrárias e Veterinárias (FCAV/UNESP)- Jaboticabal/SP

${ }^{2}$ Pós-graduando pelo Centro de Aquicultura da UNESP - Jaboticabal/SP

${ }^{3}$ Pesquisadora do Laboratório de Patologia em Organismos Aquáticos do Centro de Aquicultura da UNESP Jaboticabal/SP
} 